\title{
Deep ultraviolet copper (I) thiocyanate (CuSCN) photodetectors based on coplanar nanogap electrodes fabricated via adhesion lithography
}

\author{
Gwenhivir Wyatt-Moon ${ }^{\dagger}$, Dimitra G. Georgiadou ${ }^{\dagger}$, James Semple ${ }^{\dagger}$ and Thomas D.

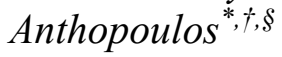 \\ ${ }^{\dagger}$ Centre for Plastic Electronics and Department of Physics, \\ Blackett Laboratory, Imperial College London, \\ London SW7 2BW, United Kingdom \\ $\S$ King Abdullah University of Science and Technology (KAUST) \\ Division of Physical Sciences and Engineering, \\ Thuwal 23955-6900, Saudi Arabia
}

Keywords: photodiode, responsivity, photosensitivity, solution-processed, coplanar electrodes

\begin{abstract}
Adhesion lithography (a-Lith) is a versatile fabrication technique used to produce asymmetric coplanar electrodes separated by a $<15 \mathrm{~nm}$ nanogap. Here we use a-Lith to fabricate deep ultraviolet (DUV) photodetectors by combining coplanar asymmetric nanogap electrode architectures $(\mathrm{Au} / \mathrm{Al})$ with the solution-processable wide band gap (3.5-3.9 eV) p-type semiconductor copper $(\mathrm{I})$ thiocyanate $(\mathrm{CuSCN})$. Due to the device's unique architecture, the detectors exhibit high responsivity $(\approx 79 \mathrm{~A} / \mathrm{W})$ and photosensitivity $(\approx 720)$ when illuminated with a DUV range $\left(\lambda_{\text {peak }}=280 \mathrm{~nm}\right)$ light-emitting diode at $220 \mu \mathrm{W} \mathrm{cm}{ }^{-2}$. Interestingly, the photosensitivity of the photodetectors remains fairly high $(\approx 7)$ even at illuminating intensities down to $0.2 \mu \mathrm{W} \mathrm{cm} \mathrm{cm}^{-2}$. The scalability of the a-Lith process combined with the unique properties of $\mathrm{CuSCN}$ pave the way to new forms of inexpensive, yet high-performance, photodetectors that can be manufactured on arbitrary substrate materials including plastic.
\end{abstract}




\section{INTRODUCTION}

Deep ultraviolet (DUV) photodetectors have many commercial applications, such as chemical and biological analysis and monitoring, optical communications and flame detection ${ }^{1}$. These often require visible-blind detectors showing high sensitivity as well as increased stability and reproducibility. Current research on DUV photodetectors is based mainly on wide band gap inorganic materials, such as silicon carbide $(\mathrm{SiC})^{2,3}$, diamond ${ }^{4,5}$, gallium nitride $(\mathrm{GaN})^{6}$ and gallium oxide $\left(\beta-\mathrm{Ga}_{2} \mathrm{O}_{3}\right)^{7-13}$. In an effort to improve the device performance a recent study used the intermediate band structure semiconductor $\mathrm{Bi}_{\mathrm{x}} \mathrm{Sn}_{1-\mathrm{x}} \mathrm{O}_{2}$ to increase the detector's responsivity while decreasing the dark current albeit with adverse effect on the visible-blind nature of the device $^{14}$. Although these devices are characterised by high performance and are suitable for use in harsh environments, they rely on laborious fabrication processes, which renders them impractical for lower cost applications. To address this challenge, some studies on organic materials, which are known for their ease of processing, have also been reported. For example, N,N-bis(naphthalen-1-yl)-N,N-bis(phenyl)benzidine $\quad(N P B)^{15}, \quad$ NPB $\quad$ with $\quad$ bis(2-methyl-8quinolinolato) (4-phenylphenolato) $\mathrm{Al}$ (BAlq) ${ }^{16}$ and 4,4',4"-tri-(2-methylphenyl phenylamino) triphenylaine (m-MTDATA) with 4,7-diphenyl-1,10-phenanthroline-(bathophenanthroline) (Bphen $)^{17}$ have been employed in organic photodetector (OPD) devices. These devices, however, not only have to rely on thermal evaporation of the active layers but also exhibit moderate device performance. Fully or partially solution-processed devices have been demonstrated based on sodium tantalate $\left(\mathrm{NaTaO}_{3}\right)^{18}, \mathrm{NaTaO}_{3}$ and 1,3,5-tri(m-pyrid-3-yl-phenyl) benzene (TmPyPB $)^{19}$ and graphene quantum dots ${ }^{20}$, but still their performance cannot compete with the non-printed devices. Table 1 summarises the performance characteristics of best DUV photodiodes based on the above mentioned materials as well as those developed in this work. 
Recently, there has been a push for developing flexible sensors for healthcare applications. An application of particular interest is sunlight sensors that detects UV photons. There are two bands of UV light that reach the earth surface and are harmful to human skin; UVA (320-400 nm) and UVB (280-320 nm). The latter is considered more harmful causing not only sunburn but direct deoxyribonucleic acid (DNA) damage and potentially cancer ${ }^{21}$. If consumers were able to monitor and reduce their UVB exposure this would help decrease this risk. Devices that are currently commercially available are all based on photochemical cells, where there is a change in state of material that determines the level of UV exposure ${ }^{22}$. The latter is a disposable single-use device and not very effective at distinguishing between the different UV bands. Although research into electronic devices for this application was initiated in the $1990 \mathrm{~s}^{23}$, little has been achieved so far. Only in the last few years there have been some reports on flexible UV diodes for sunlight detection. Dang et al. reported on zinc oxide ( $\mathrm{ZnO})$-nanorod/graphene hybrid field effect transistors (FETs) showing high responsivity and mechanical robustness ${ }^{24}$. However $\mathrm{ZnO}$ absorbs strongly in UVA band and makes no distinction between UVA and UVB bands, which is critical for providing accurate information to the end-user. Furthermore, their devices were only tested at $365 \mathrm{~nm}$, and as such their sensitivity to the UVB range remains unknown. Another study reported the development of DUV detectors based on zinc germanate $\left(\mathrm{Zn}_{2} \mathrm{GeO}_{4}\right)$ and indium germanate $\left(\mathrm{In}_{2} \mathrm{Ge}_{2} \mathrm{O}_{7}\right)$ nanowire mats ${ }^{25}$. The devices exhibited high stability under mechanical stress but, due to the use of chemical vapour deposition growth technique, the use of the technology for costefficient manufacturing of devices over large-area arbitrary substrate materials remains questionable.

To create UV band specific devices with high performance that also fulfil the requirements for fabrication on flexible substrates, new materials and device concepts need to be introduced. A 
promising candidate material that has been recently employed in plastic electronics is copper (I) thiocyanate $(\mathrm{CuSCN})^{26}$. $\mathrm{CuSCN}$ is a p-type wide bandgap 3.5-3.9 eV (WBG) semiconductor material that only absorbs in the DUV region ${ }^{27}$. It has recently been used as hole transport layer (HTL) to improve the efficiency and stability of organic light emitting diodes (OLEDs) and organic and perovskite solar cells ${ }^{28-31}$. One of its main attributes is the ease of deposition, as it can be solution-processed from non-toxic solvents at low temperatures (below $110^{\circ} \mathrm{C}$ ). $\mathrm{CuSCN}$ has also been employed along with $\mathrm{ZnO}$ nanostructures to form PN heterojunctions for UVA photodetectors $^{32-34}$ but, to the best of our knowledge, it has never been used as the photoactive material component. Moreover, a recent study showed that CuSCN-based transistors and inverter circuits performed well under mechanical stress demonstrating its potential for printed flexible electronics ${ }^{35}$.

From the photodetector device fabrication standpoint, one must take the essential attributes of the different possible architectures into consideration. A device structure commonly used in such optoelectronic applications is a vertical (sandwich) configuration of metal electrodes and active layer(s) (Figure 1A). This requires the need for at least one electrode being transparent to the DUV part of the spectrum, which is not trivial as most available substrates absorb DUV light. A more convenient architecture is the planar metal-semiconductor-metal (MSM) structure, as in this case nanostructured (2D) materials can be employed ${ }^{36}$, which allow for top illumination of the photodetector (Figure 1B). Our group has previously demonstrated an innovative patterning technique, namely adhesion lithography (a-Lith), for the fabrication of coplanar electrodes separated by a sub-15 nm nanogap ${ }^{34}$ (Figure 1C). Devices manufactured via a-Lith not only offer the benefits of a purely coplanar (top-illuminated) nanogap architecture but also of the ability to incorporate dissimilar (asymmetric) electrodes that could act as the cathode and anode, depending 
on the particular choice of the electrode material. These unique attributes are expected to increase the photodetector operating characteristics, including speed and photosensitivity.

Here, we report on solution-processed CuSCN-based nanogap DUV photodetectors fabricated via adhesion lithography at low temperatures. The unique coplanar nanogap diode architecture combined with the wide bandgap characteristics of CuSCN results in photodiodes with low dark currents, high responsivity and sensitivity in the DUV region. Analysis of the diodes' spectral response reveals their visible-blind nature, and highlights the potential of the technology for UV detector applications. Importantly, variation of the device's nanogap width from 1 to $10 \mathrm{~cm}$, allowed significant increase of the photocurrent, whilst retaining the diode's low dark current. These results pave the way to fabrication of a novel form of UV photodetectors utilizing $\mathrm{CuSCN}$ as the active material and a-Lith as the manufacturing technique.

\section{EXPERIMENTAL SECTION}

\subsection{Structure and Photodetector Device Fabrication via Adhesion Lithography}

Pairs of aluminium $(\mathrm{Al})$ and gold $(\mathrm{Au})$ electrodes separated by $<15 \mathrm{~nm}$ nanogaps were fabricated using the adhesion lithography (a-Lith) technique ${ }^{37,38}$. The various process steps are shown in Figure 2A. More specifically, patterned interdigitated Al/Au electrodes with various widths, 1, 2, 5 and $10 \mathrm{~cm}$, were fabricated by first evaporating $40 \mathrm{~nm}$ thick $\mathrm{Al}$ onto borosilicate glass substrates and patterning it using a standard contact photolithography produce with S1813 (microposit) employed as the photoresist (step 1). Octadecylphosphonic acid (ODPA, purchased from SigmaAldrich) was used to functionalize the surface of the lightly oxidized Al electrode via substrate 
immersion in an ODPA solution in 2-propanol (IPA) for $3 \mathrm{~h}$ (step 2). Next, a $35 \mathrm{~nm}$ layer of $\mathrm{Au}$ with a $5 \mathrm{~nm}$ adhesive layer of $\mathrm{Al}$ (not shown in the schematic) was evaporated on top (step 3 ). This $\mathrm{Au}$ layer adheres well to the substrate but not to the ODPA-covered Al due to its hydrophobic nature. A commercially available adhesive glue (First Contact, from Photonic Cleaning Technologies) was applied to the top Au surface and left to dry for $\sim 20 \mathrm{~min}$. This was then peeled off, selectively removing the gold from the areas of the ODPA-covered Al (step 4). The ODPA was removed using UV-Ozone treatment for 5 min revealing the empty nanogap (step 5). A second contact lithography step was performed to electrically isolate the distinct devices by patterning S1813 and selectively etching the Au and Al using commercially bought metal etchants to obtain the structures shown in Figure 2B. For the fabrication of photodiodes, first copper (I) thiocyanate (CuSCN, purchased from Sigma Aldrich) was dissolved in diethyl sulfide (DES) at a concentration of $15 \mathrm{mg} / \mathrm{ml}$ and left to stir for $2 \mathrm{~h}$. The a-Lith defined nanogap electrodes were placed in the UVOzone for $30 \mathrm{~min}$ prior to $\mathrm{CuSCN}$ deposition. The solution was then spin-coated at $2000 \mathrm{rpm}$ for 60 s onto the patterned $\mathrm{Al} / \mathrm{Au}$ electrodes in a dry nitrogen glovebox and subsequently annealed at $110^{\circ} \mathrm{C}$ for $15 \mathrm{~min}$.

\subsection{A-Lith Substrate and Thin Film Characterisation}

The empty Al/Au nanogap metal electrodes were characterised using a LEO Gemini 1525 Field Emission Scanning Electron Microscope (FESEM) with the operating voltage at $5 \mathrm{kV}$. The surface morphologies of the empty nanogap structures and $\mathrm{CuSCN}$ thin films on glass and on a-Lith patterned electrodes were investigated using an Agilent 5500 Atomic Force Microscope (AFM) in intermittent contact mode. For absorption measurements, $\mathrm{CuSCN}$ films were spin-coated on quartz 
substrates using the same process as above, and were measured in air using a Shimadzu 2600 $\mathrm{UV}-\mathrm{V}$ is spectrophotometer.

\subsection{Photodetector Optoelectronic Characterisation}

Current-voltage characteristics and response times of the photodiodes was carried out using an Agilent B2902A source/measure unit. Optoelectronic characterisation was performed using lightemitting diodes (LEDs) emitting at $280 \mathrm{~nm}$ at various optical power levels, and at $390 \mathrm{~nm}, 475$ $\mathrm{nm}, 525 \mathrm{~nm}$ and $625 \mathrm{~nm}$ at an optical power density of $90 \mu \mathrm{W} \mathrm{cm}{ }^{-2}$. The LED current was controlled with a Keithley 2400 source meter. The spectra of the LEDs were characterised using an Ocean Optics spectrometer, while the optical power was measured using a calibrated optical power meter (PM120V Thor Labs). All measurements were carried out at room temperature in a dry nitrogen-filled glovebox.

\section{RESULTS AND DISCUSSION}

\subsection{Coplanar Electrodes Fabrication and CuSCN Thin Film Characterisation}

The a-Lith patterning technique has been so far successfully applied to fabricate $<15 \mathrm{~nm}$ separated electrodes of various shapes and sizes ${ }^{37,38,39}$. Herein, we show that a-Lith can easily be extended to more complicated geometries, allowing for the customisation of electrodes shape and size tailored to the specific application. In this instance, asymmetric $\mathrm{Au} / \mathrm{Al}$ interdigitated electrodes of varying size (and thus diode width) were selected to allow for the greatest photocurrent effect in 
the respective photodetectors. Figure 2B depicts the optical micrographs of the actual electrodes used, including devices of different electrode width depending on the pitch separation and, thus, the total perimeter of each structure. It is noteworthy that the $<15 \mathrm{~nm}$ nanogap separating the two electrodes is quite uniform as revealed by the AFM and SEM micrographs shown in Figures 2C and 2D, respectively.

These substrates were then used to fabricate DUV photodetectors by spin-coating a thin film of CuSCN from its solution in DES. Note that CuSCN generally forms quite smooth nanocrystalline films $(\mathrm{rms}=5.9 \mathrm{~nm})$, as can be seen in the AFM micrograph shown in the inset of Figure 3 in good agreement with previously reported data ${ }^{40,41}$. The most important property of CuSCN film for this application, however, is its absorption spectrum (Figure 3), which shows a good overlap with the spectrum of the LED emitting at the UVB region, and almost no absorption at UVA, visible and NIR parts of the optical spectrum, as well as with the spectra of the other LEDs used later to excite the photodiodes. These spectral characteristics suggest that $\mathrm{CuSCN}$ is an ideal candidate to be implemented in visible-blind photodetectors that operate in the DUV/UVB region.

To form the coplanar nanogap DUV photodetectors, CuSCN was spin-coated on top of the aLith patterned asymmetric Al/Au electrodes described above, a side view of which is shown in the schematic in Figure 4A. The top-view 3D AFM topography of this (Figure 4B) indicates that the $\mathrm{CuSCN}$ film covers the electrodes with an indent on the CuSCN just being discerned above the nanogap area. The semiconducting layer, however, is continuous and with an RMS roughness of $4.1 \mathrm{~nm}$.

\subsection{Photodiode Electrical Characterization}


The selection of the metal electrodes was based on the band diagram (flat band configuration) depicted in Figure 4C. The Fermi level of CuSCN has previously been reported to lie at about 5.0$5.1 \mathrm{eV}^{30}$, so an Ohmic contact would be expected at the Au/CuSCN interface and a Schottky contact should be formed with the Al electrode due to the large energetic barrier $(\sim 1 \mathrm{~V})$ between CuSCN Fermi level and the Al electrode work function. This means that a Schottky diode is expected when employing this device structure, which is beneficial for this application as it should lead to low dark currents, high rectification ratio and potentially fast dynamic response. The semilogarithmic plot of the I-V characteristic of the $\mathrm{CuSCN}$ device measured in the dark (Figure 5A) proves the rectifying nature of the diode with a turn-on voltage of $\sim 0.6 \mathrm{~V}$ and a rectification ratio (RR) of about $10^{3}$. We attribute this to the ultra-low dimensionality and the co-planar architecture of the nanogap electrodes, which help minimise the series resistance ${ }^{42}$. Furthermore, the low reverse dark current, the value of which reaches the limits of our measurement setup, confirms the Schottky contact formation between $\mathrm{Al}$ and $\mathrm{CuSCN}$, as opposed to the expected Ohmic nature of the $\mathrm{Au} / \mathrm{CuSCN}$ contact that allows current to flow in the forward bias direction. However, when the sample is illuminated with the $280 \mathrm{~nm}$ emitting LED at an optical power density of $220 \mu \mathrm{W}$ $\mathrm{cm}^{-2}$, the current at $-2 \mathrm{~V}$ is found to increase over 3 orders of magnitude, as compared to the dark current. This high photoresponse proves the ability of these prototypical coplanar nanogap CuSCN-based diodes to detect DUV.

To further characterise the a-Lith photodiodes, the values of two commonly employed figures of merit, namely responsivity (R) and photosensitivity (PS), were calculated. More specifically, R is the ratio of the change in the current upon illumination, $\Delta \mathrm{I}=\mathrm{I}_{\mathrm{PD}}-\mathrm{I}_{\mathrm{dark}}$, divided by the incident optical power, $\mathrm{P}$, with this incident power taking the device area into account $(\mathrm{R}=\Delta \mathrm{I} / \mathrm{P})$. Device illumination area was calculated by taking the product of electrode separation, estimated at $\sim 15$ 
$\mathrm{nm}$, and the device width. $\mathrm{R}$ depends on the applied bias and wavelength of the excitation source. PS is the change in current due to illumination at a certain applied bias with respect to the dark current at that bias (PS $\left.=\Delta \mathrm{I} / \mathrm{I}_{\text {dark }}\right)$. The devices shown in Figure 5A have an $\mathrm{R}=79 \mathrm{~A} / \mathrm{W}$ and PS $=720$. These values are very high and, to the best of our knowledge, are only surpassed by two other reported devices that were fabricated using comparatively complicated techniques, such as chemical vapour deposition $(\mathrm{CVD})^{7}$ and CVD with focused ion beam milling $(\mathrm{FIB})^{8}$ (see Table 1). One of the main reasons for the high responsivity is likely the low-dimensional nature of the nanogap electrode geometry enabled by a-Lith.

The response time of the device was also investigated. Figure 5B shows the evolution of photocurrent with time for a nanogap $\mathrm{CuSCN}$ diode biased at $-2 \mathrm{~V}$ upon pulsed illumination with a $280 \mathrm{~nm}\left(\lambda_{\max }\right)$ LED. Here the inorganic LED is initially switched on for $25 \mathrm{~s}$ and then switched off. Note that the higher off-current shown on this graph is due to different measurement parameters and higher data acquisition speed, and not due to device degradation. Analysis of the response yields a rise time of $\approx 1 \mathrm{~s}$ and a fall time on the order of $10 \mathrm{~s}$ of seconds, although the latter can be subdivided into a short-time (4-10 s) and a long-time ( $>10 \mathrm{~s})$ components. We note that the raise and fall times are longer than previously reported values for DUV photodetectors (Table 1). There may be a few different reasons for this observations including ion migration due to the proposed semi-ionic character of $\mathrm{CuSCN}^{43}$, and/or the presence of deep trap states in solutiondeposited $\mathrm{CuSCN}$ layers ${ }^{44,45}$. Although, ionic displacement would be expected to be faster due to the $\mathrm{nm}$ dimensions of the $\mathrm{Au} / \mathrm{CuSCN} / \mathrm{Al}$ nanogap, slow carrier detrapping from deep trap states maybe a more plausible mechanism responsible for the persistent photoconductivity behaviour observed as the latter are known to exist in solution processed $\mathrm{CuSCN}^{44}$. Therefore, it is clear that microstructural optimization of the $\mathrm{CuSCN}$ layer, could yield detectors with faster photoresponse 
while intentional $p$-doping may lead to deep trap deactivation and hence to further device performance improvements.

Figure 5C shows the photocurrent at $-2 \mathrm{~V}$ bias at different incident optical power densities. The $\log -\log$ plot shows a square root dependence of the current on the optical power. This is mostly likely due to carrier trapping, recombination and electron-hole generation within the semiconductor $^{12,46}$. Importantly, from this data it can be seen that the photosensitivity of the nanogap DUV detectors remains high $(\sim 7)$ even at an illumination intensity of $0.2 \mu \mathrm{W} \mathrm{cm}{ }^{-2}$ for which the device current measured under illumination is over an order of magnitude larger than the dark current.

When the nanogap photodiode was illuminated with LEDs emitting at wavelengths in the visible region $(470,522$, and $630 \mathrm{~nm})$, the diode characteristics remained unchanged and similar to the dark I-V curve (Figure 6A), confirming that these photodiodes are visible-blind due to the wide bandgap nature of CuSCN. However, under $390 \mathrm{~nm}$ illumination there is a slight change in the IV characteristic, with the responsivity increasing an order of magnitude as compared to that during visible light illumination (Figure 6B). The latter cannot be attributed solely to the absorption spectrum of CuSCN (overlaid in Figure 6B for clarity). To this end, $\mathrm{CuSCN}$ has been reported to have a transmittance of $86 \%$ at $\approx 390 \mathrm{~nm}$, as compared to $>90 \%$ for wavelengths $>450 \mathrm{~nm}^{40}$. The respective optical absorption at this wavelength could be enhanced when light is passing through a nanoscale metal slit filled with a semiconducting absorbing material due to resonant excitation of the fundamental field-symmetric surface plasmon-polariton (SPP) mode supported by the slit 47, 48 . Therefore, a plausible explanation for the observed small photoresponse could be that the SPP effect caused by the $\mathrm{Au} / \mathrm{Al}$ interdigitated nanogap structure enhances the absorption of photons with a wavelength of $390 \mathrm{~nm}$, followed by an indirect transfer of carriers from the 
photoexcited bands of the metal to the conduction band of the semiconductor; however direct creation/injection of charge carriers in the $\mathrm{CuSCN}$ cannot be ruled out ${ }^{49}$. A more detailed spectroscopic characterisation, which is beyond the scope of this study, would be required to either prove or refute one mechanism over the other.

\subsubsection{Varying the Width of Nanogap CuSCN Photodiodes}

From a fabrication point of view, a very attractive feature of a-Lith is that it can be tailored according to the specifications posed for each application in terms of electrode materials, size and shape, whilst maintaining the inter-electrode nanogap constant and typically below $15 \mathrm{~nm}$. Here the diode width was scaled at will to optimise the device performance. Figure 7A shows the I-V characteristics of four diodes with different widths $(1,2,5$ and $10 \mathrm{~cm})$ measured in the dark. As expected, increasing the nanogap width leads to enhanced forward current but with the reverse current remaining low and relatively constant for all devices due to the effective Schottky contact that is being formed between $\mathrm{Al}$ and $\mathrm{CuSCN}$. When the same devices are irradiated with the UVLED emitting at $280 \mathrm{~nm}$, the measured photocurrent is found to increase with increasing nanogap width. This effect is better illustrated in Figure 7B where the photocurrent measured at $-2 \mathrm{~V}$ is nearly 10 times higher for the $10 \mathrm{~cm}$ device than that measured for the $1 \mathrm{~cm}$ width photodiode. As a result the $10 \mathrm{~cm}$ width device exhibits a significantly enhanced photoresponse of over 4 orders of magnitude. On the basis of this data, it can be concluded that the UV photoresponse of the devices can easily be improved by scaling the diode's width. 


\section{CONCLUSIONS}

Deep UV photodiodes were fabricated using $\mathrm{CuSCN}$ as the wide bandgap light absorbing semiconductor in combination with a novel co-planar $\mathrm{Al} / \mathrm{Au}$ electrode nanogap architecture enabled by a-Lith. The resulting devices exhibited high photo-responsivity and sensitivity without the need for a transparent contact and complicated fabrication techniques or elaborate material processing. Furthermore, simple scaling of the device's nanogap width was shown to enhance the detector's photoresponse further highlighting the versatility of the a-Lith technique for the manufacturing of high performance DUV photodetectors on large-area on arbitrary substrate materials. 


\section{FIGURES}

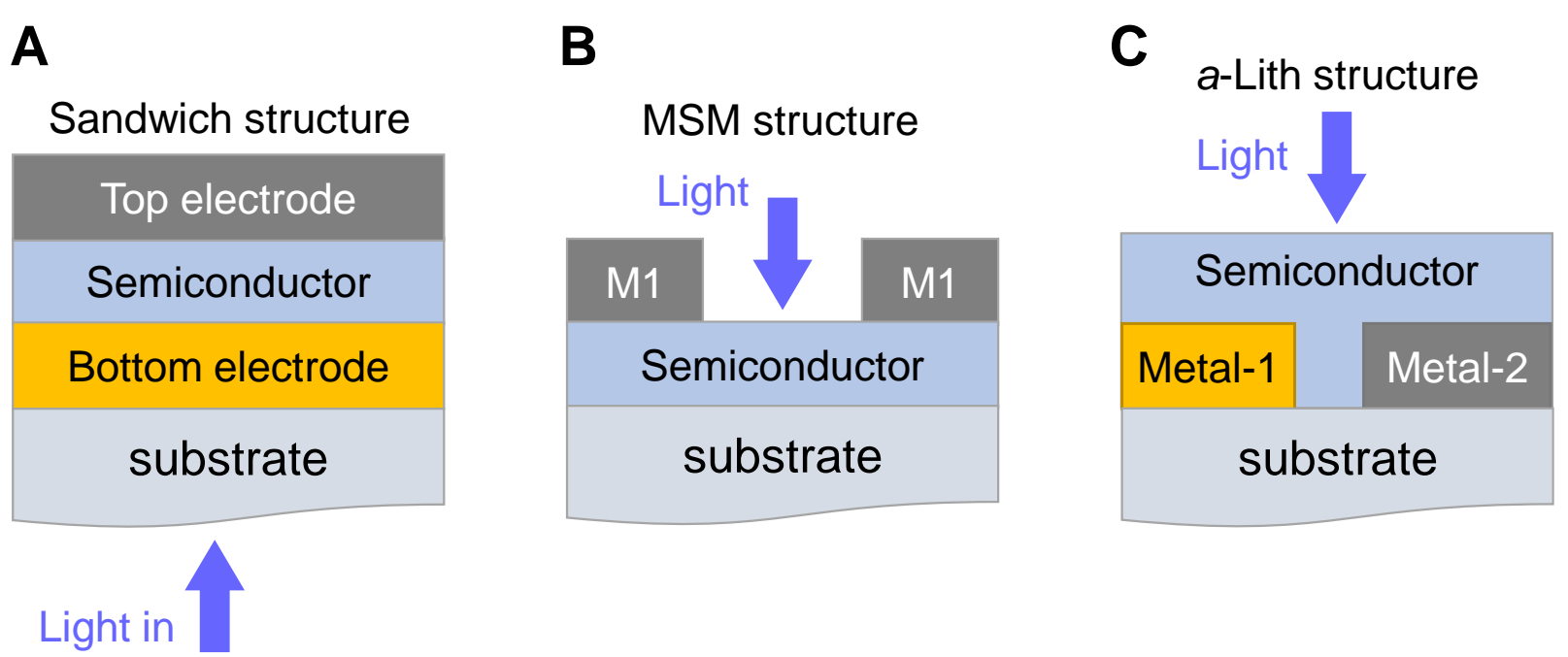

Figure 1. Different device architectures of DUV photodetectors: (A) sandwich (vertical) structure with bottom illumination through the transparent electrode, (B) Metal-semiconductor-metal planar structure, typically used with 2-dimensional materials, with symmetric contacts, and (C) a-Lith (planar) structure employing asymmetric contacts. 

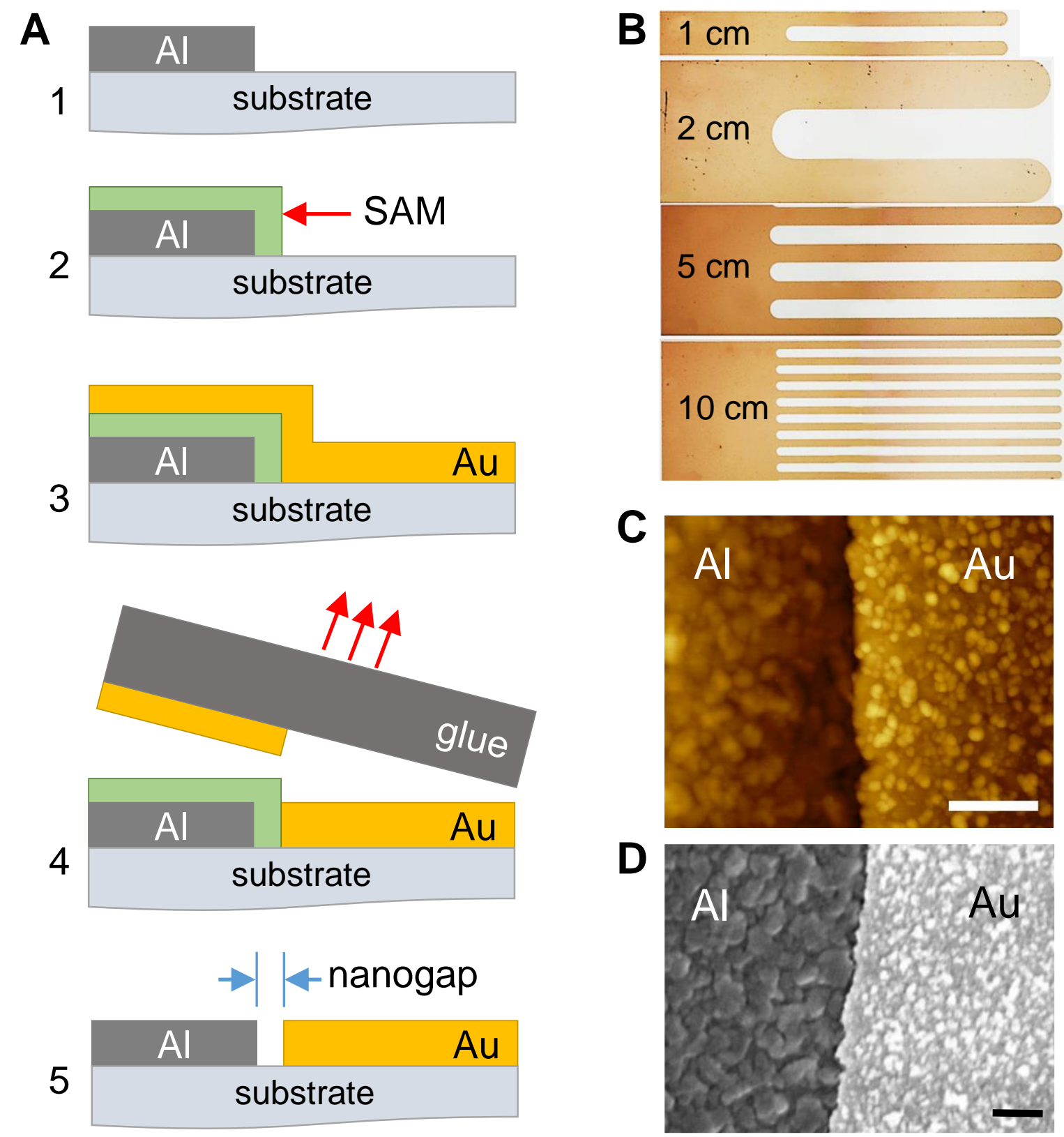

Figure 2. (A) Schematic illustration of the different adhesion lithography process steps. (B) Optical micrographs of the varying width coplanar $\mathrm{Al} / \mathrm{Au}$ interdigitated electrodes used in this study. (C) AFM topography image (peak-to-valley height: $55 \mathrm{~nm}$ ), and (D) SEM image showing the nanogap-separated Al, Au electrodes. Scale bars in (C) and (D): $200 \mathrm{~nm}$. 


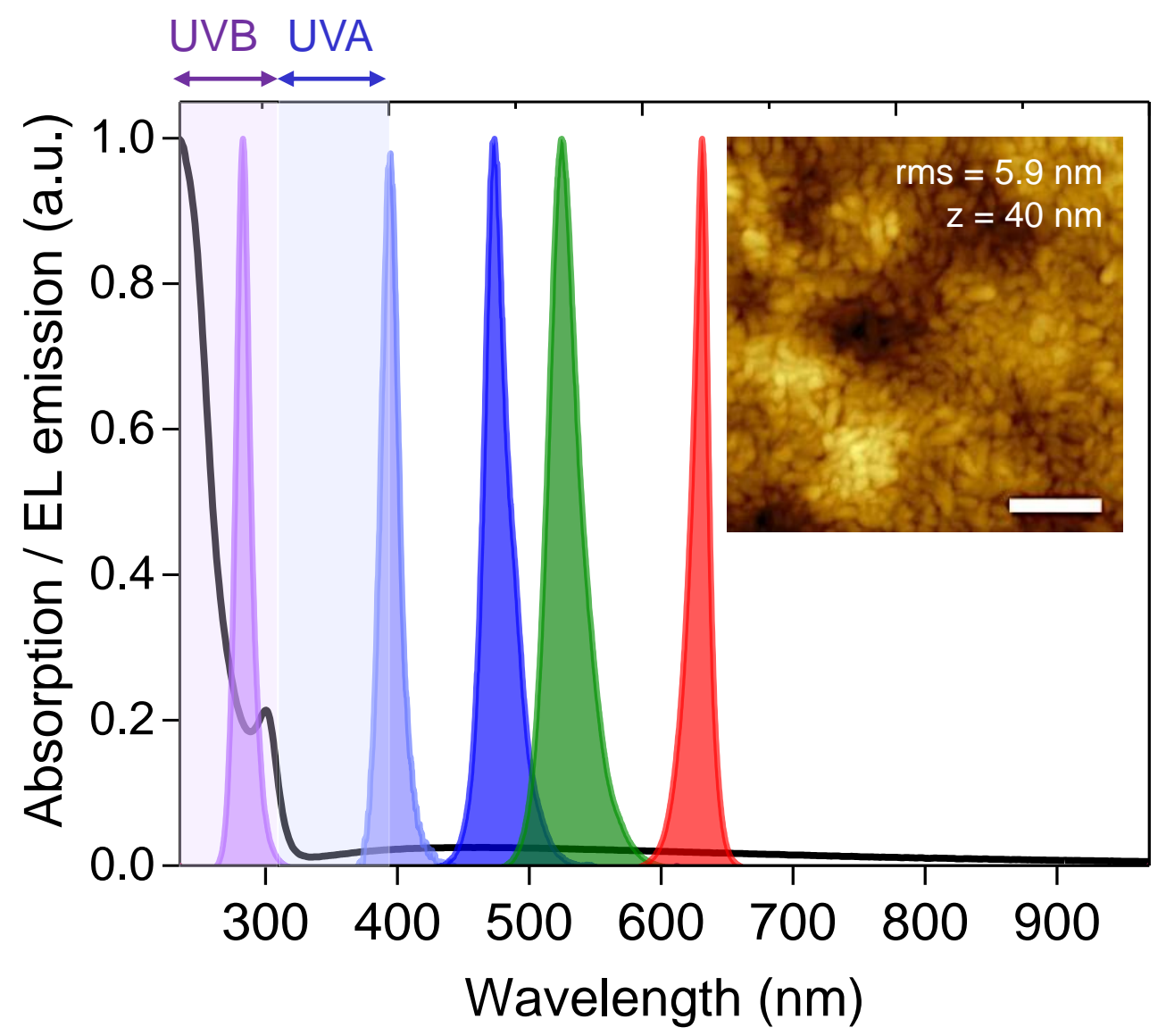

Figure 3. UV-Vis absorption spectrum of a CuSCN layer deposited on quartz substrate and the electroluminescence spectra of the inorganic LEDs used to excite the nanogap photodiode. Inset: AFM topography image of a CuSCN film deposited on glass i.e. the same substrate used for the fabrication of the photodetectors. Scale bar: $200 \mathrm{~nm}$. 


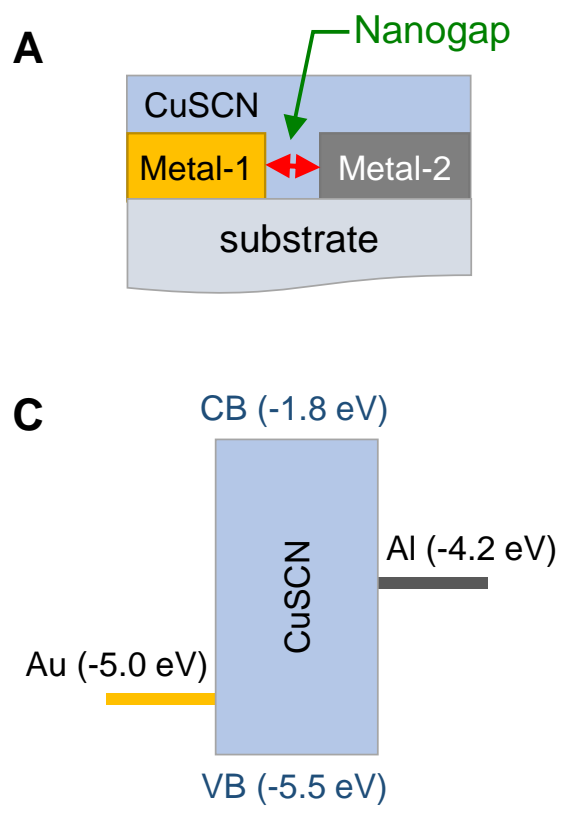

B

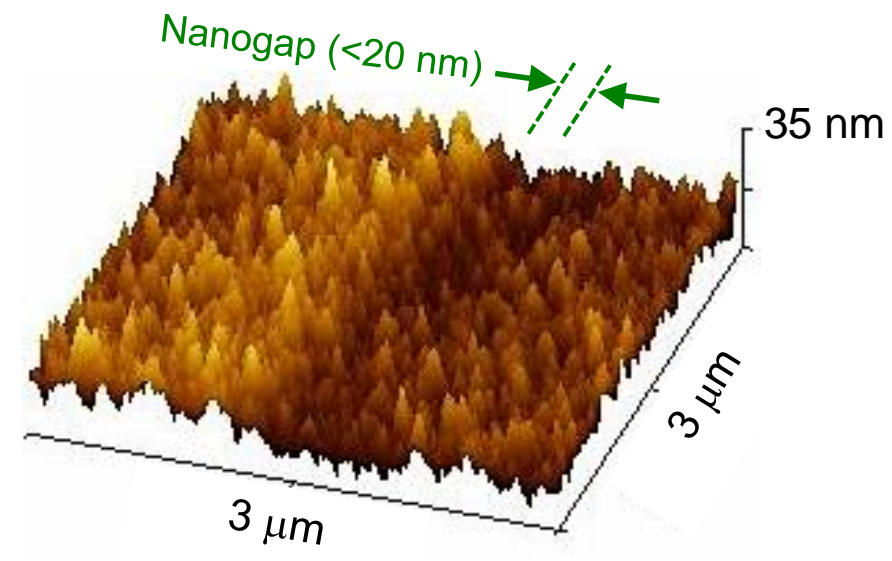

Figure 4. (A) Schematic of the coplanar nanogap photodetector device structure employed. (B) 3dimensional AFM $(3 \mu \mathrm{m} \times 3 \mu \mathrm{m})$ topography image of CuSCN layer spin-cast on top of the adhesion lithography fabricated nanogap electrodes. (C) Energy band structure of the CuSCNbased photodetector. 

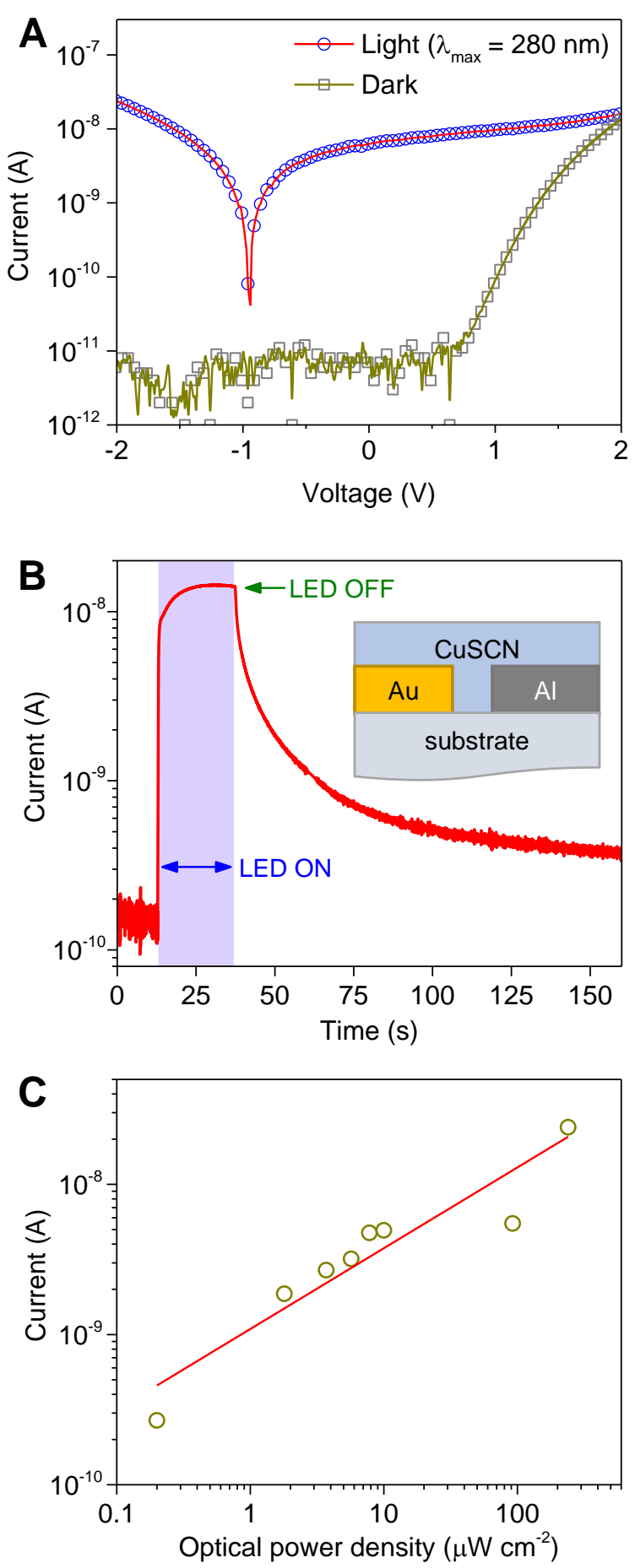

Figure 5. (A) Semi-logarithmic current-voltage plots measured for a CuSCN photodiode in the dark and under UV light illumination $\left(\lambda_{\max }=280 \mathrm{~nm}\right)$ with optical power density of $220 \mu \mathrm{W} \mathrm{\textrm {cm } ^ { - }}$ 2. (B) Dynamic response of CuSCN photodiode following continuous illumination for $25 \mathrm{~s}$ under same conditions as in (A) measured at $-2 \mathrm{~V}$. (C) Measured photodiode current at different optical power density levels $\left(\lambda_{\max }=280 \mathrm{~nm}\right)$ at $-2 \mathrm{~V}$. Red line shown the linear fit to the experimental data. 

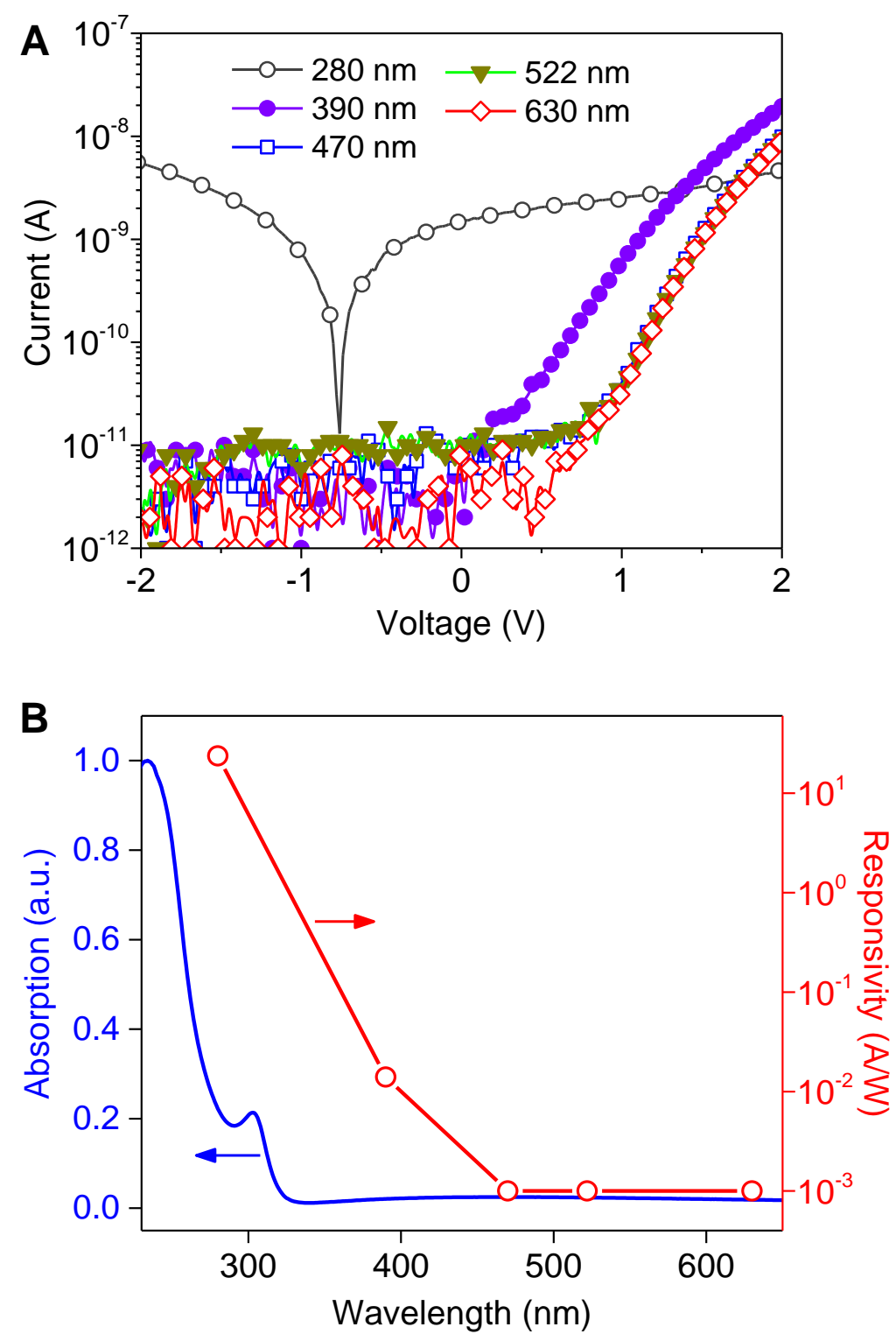

Figure 6. (A) Semi-logarithm current-voltage plots measured for a CuSCN photodiode under different illumination wavelengths $\left(\lambda_{\max }\right) ; 280 \mathrm{~nm}, 390 \mathrm{~nm}, 470 \mathrm{~nm}, 522 \mathrm{~nm}$, and $630 \mathrm{~nm}$ at a constant optical power density of $90 \mu \mathrm{W} \mathrm{cm} \mathrm{cm}^{-2}$. (B) UV-Vis absorption spectrum of CuSCN and spectral responsivity of the nanogap photodetector at $90 \mu \mathrm{W} \mathrm{cm}-2$ measured at $-2 \mathrm{~V}$. 

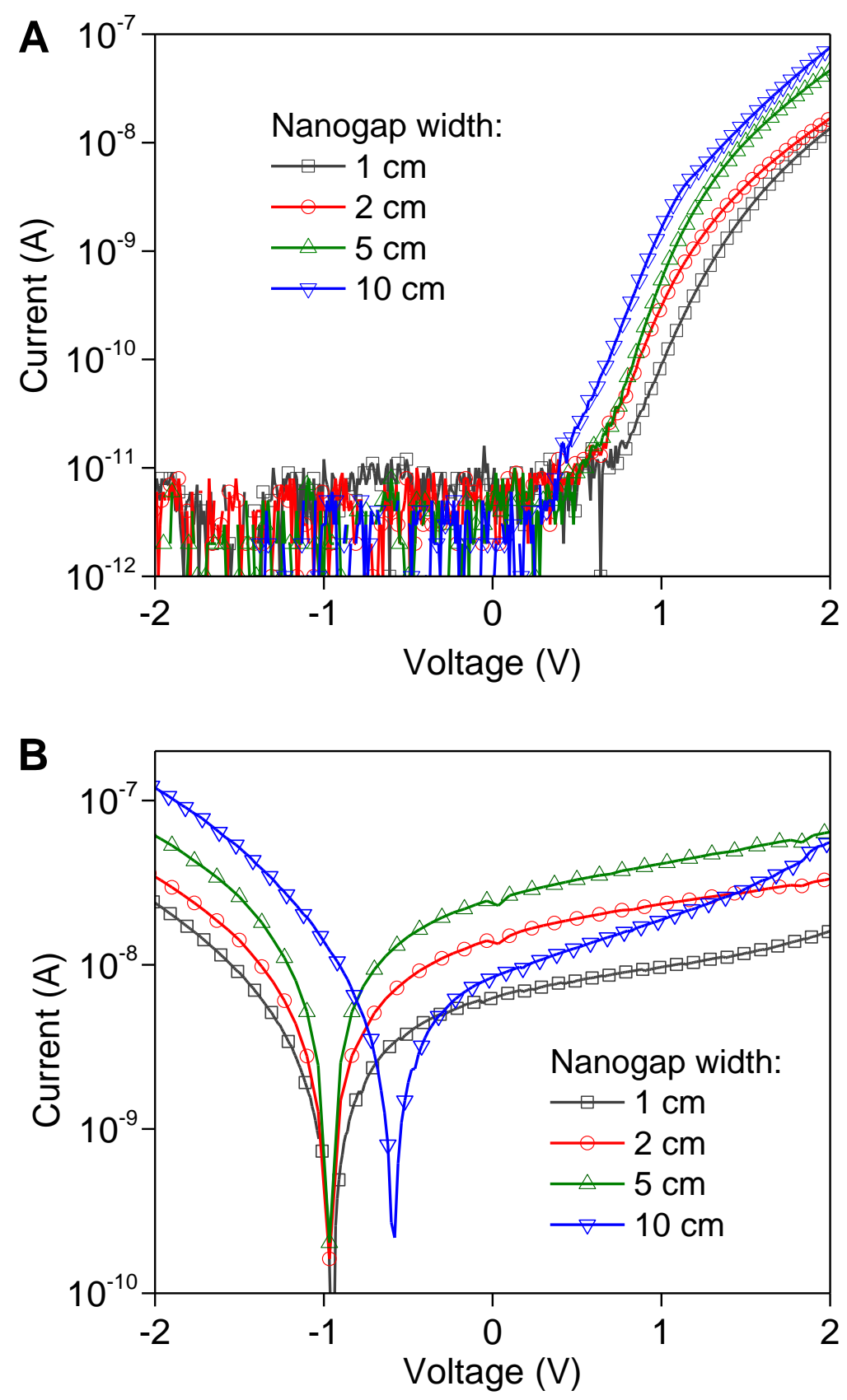

Figure 7. Semi-logarithm current-voltage plots measured for $\mathrm{CuSCN}$ photodiodes with varying width in the range $1-10 \mathrm{~cm}$. (A) Measured in the dark and (B) under illumination at $\left(\lambda_{\max }=280 \mathrm{~nm}\right.$ at an optical power density of $220 \mu \mathrm{W} \mathrm{cm}{ }^{-2}$. 


\section{ASSOCIATED CONTENT}

Table 1. Comparison of different types of DUV photodetectors found in the literature.

\begin{tabular}{|c|c|c|c|c|c|c|c|c|}
\hline Active material & $\begin{array}{l}\text { Deposition } \\
\text { method }\end{array}$ & Device type & $\begin{array}{l}\text { Wavelength } \\
(\mathbf{n m})\end{array}$ & $\begin{array}{l}\text { Intensity } \\
\left(\mathrm{mW} / \mathrm{cm}^{2}\right)\end{array}$ & $\begin{array}{c}\text { Responsivity } \\
\text { (A/W) }\end{array}$ & $\begin{array}{c}\text { Voltage } \\
\text { (V) }\end{array}$ & $\begin{array}{c}\text { Response } \\
\text { time }\end{array}$ & Ref. \\
\hline Silicon Carbide & Laser plasma & MSM & 250 & 2 & 0.18 & 10 & $90 \mathrm{~s}$ & {$[2]$} \\
\hline$\beta-\mathrm{Ga}_{2} \mathrm{O}_{3} /$ diamond & CVD & MSM & 240 & $\mathrm{n} / \mathrm{a}$ & & 16 & $>0.3 \mathrm{~s}$ & {$[4]$} \\
\hline $\mathrm{GaN}$ & $\begin{array}{l}\text { CVD on } \mathrm{GaN} \\
\text { wafer }\end{array}$ & planar pin diode & 280 & $\mathrm{n} / \mathrm{a}$ & 0.15 at $0 \mathrm{~V}$ & $0-92$ & $1 \mu \mathrm{s}$ & {$[6]$} \\
\hline $\begin{array}{l}\beta-\mathrm{Ga}_{2} \mathrm{O}_{3} \\
\text { nanowires }\end{array}$ & CVD & MSM & 254 & 0.07 & 377 & 10 & $1.20 \mathrm{~ns}$ & [7] \\
\hline $\begin{array}{l}\mathrm{ZnO}-\mathrm{Ga}_{2} \mathrm{O}_{3} \\
\text { core-shell } \\
\text { microwires. }\end{array}$ & CVD and FIB & $\begin{array}{l}\text { MSM with } \\
\text { In and } \mathrm{Ti} / \mathrm{AU} \\
\text { electrodes }\end{array}$ & 254 & 1.67 & 3000 & 6 & $20 \mu \mathrm{s}$ & {$[8]$} \\
\hline$\beta-\mathrm{Ga}_{2} \mathrm{O}_{3} / \mathrm{SiC}$ & $\begin{array}{l}\text { Thermal } \\
\text { evaporation on } \\
\text { SiC wafer }\end{array}$ & Sandwich & $210-260$ & 40 & $0.07-0.04$ & 2 & $\mathrm{~ms}$ & [9] \\
\hline$\beta-\mathrm{Ga}_{2} \mathrm{O}_{3} / \mathrm{NSTO}$ & sputtering & Sandwich & 254 & 0.045 & 43 & 10 & $0.07 \mathrm{~s}$ & {$[11]$} \\
\hline NPB and PBD & $\begin{array}{l}\text { Thermal } \\
\text { Evaporation }\end{array}$ & Sandwich & 280 & 0.488 & 0.18 & 12 & $\mathrm{n} / \mathrm{a}$ & [12] \\
\hline NPB and BAlq & $\begin{array}{l}\text { Thermal } \\
\text { Evaporation }\end{array}$ & Sandwich & 270 & 1.35 & 0.014 & 12 & $\mathrm{n} / \mathrm{a}$ & [13] \\
\hline $\begin{array}{l}\text { m-MTDATA and } \\
\text { Bpen }\end{array}$ & $\begin{array}{l}\text { Thermal } \\
\text { evaporation }\end{array}$ & Sandwich & 280 & 0.428 & 0.309 & 8 & $\mathrm{n} / \mathrm{a}$ & [14] \\
\hline $\mathrm{NaTaO}_{3}$ & solution & MSM & 260 & 0.135 & 0.0415 & 5 & $\mathrm{n} / \mathrm{a}$ & {$[15]$} \\
\hline $\begin{array}{l}\text { TmPyPB/Py- } \\
\mathrm{NaTaO}_{3} \mathrm{NCs}\end{array}$ & solution & Sandwich & 280 & 5 & 0.02 & 3 & $0.22 \mathrm{~s}$ & [16] \\
\hline $\begin{array}{l}\text { Graphene } \\
\text { Quantum Dots }\end{array}$ & Solution & $\begin{array}{l}\text { MSM with } \mathrm{Au} \\
\text { and } \mathrm{Ag} \\
\text { electrodes }\end{array}$ & 254 & 0.042 & 0.002 & 5 & $64 \mathrm{~ms}$ & [17] \\
\hline $\mathrm{CuSCN}$ & Solution & $\begin{array}{l}\text { MSM with Al \& } \\
\text { Au electrodes }\end{array}$ & 280 & 0.220 & 79 & 2 & $1-50 \mathrm{~s}$ & $\begin{array}{l}\text { This } \\
\text { work }\end{array}$ \\
\hline
\end{tabular}




\section{AUTHOR INFORMATION}

\section{Corresponding Author}

*E-mail: thomas.anthopoulos@kaust.edu.sa. Corresponding author address: King Abdullah University of Science and Technology (KAUST), Division of Physical Sciences and Engineering,

Thuwal 23955-6900, Saudi Arabia.

\section{Author Contributions}

G.W.M and T.D.A. designed the experiments. G.W.M performed the AFM, SEM, UV-Vis and device measurements. G.W.M, D.G.G. and T.D.A. analysed the measured data and wrote the article. All authors have given approval to the final version of the manuscript.

\section{FUNDING SOURCES}

G.W.M. and T.D.A. acknowledge the Engineering and Physical Sciences Research Council (EPSRC) grant no. EP/G037515/1. D.G.G. and T.D.A. acknowledge financial support from the European Union's Horizon 2020 research and innovation programme (under the Marie Skłodowska-Curie grant agreement 706707).

\footnotetext{
ABBREVIATIONS

DUV $=$ Deep Ultraviolet, $\mathrm{PD}=$ Photodiode, $\mathrm{a}-$ Lith $=$ adhesion Lithography, $\mathrm{LED}=$ Light Emitting Diode, $\mathrm{AFM}=$ Atomic Force Microscopy, $\mathrm{SEM}=$ Scanning Electron Microscopy, $\mathrm{WBG}=\mathrm{Wide}$ Band Gap.
} 


\section{REFERENCES}

(1) Monroy, E.; Omn F. S.; Calle F. Wide-bandgap semiconductor ultraviolet photodetectors Semicond. Sci. Technol. 2003, 18, 4, 33-51.

(2) Aldalbahi, A.; Li, E.; Rivera, M.; Velazquez, R.; Altalhi, T.; Peng, X.; Feng, P. X. A new approach for fabrications of SiC based photodetectors Sci. Rep. 2016, 6, 23457.

(3) Anderson, T. J.; Hobart, K. D.; Greenlee, J. D.; Shahin, D. I.; Koehler, A. D.; Tadjer, M. J.;. Imhoff A. E.; Myers-Ward, L. A.; Christou, A.; Kub, F. J. Ultraviolet detector based on graphene/SiC heterojunction, Appl. Phys. Express 2015, 8, 041301.

(4) Sang, L.; Hu, J.; Zou, R.; Koide, Y.; Liao, M. Arbitrary multicolor photodetection by heterointegrated semiconductor nanostructures Sci. Rep. 2013, 3, 2368.

(5) Liao, M.; Koide, Y.; Alvarez, J. Single Schottky-barrier photodiode with interdigitatedfinger geometry: Application to diamond Appl. Phys. Lett. 2007, 90, 123507.

(6) Shen, S. C.; Zhang, Y.; Yoo, D.; Limb, J. B.; Ryou, J. H.; Yoder, P. D.; Dupuis, R. D. Performance of deep ultraviolet $\mathrm{GaN}$ avalanche photodiodes grown by MOCVD IEEE Photonics Technol. Lett. 2007, 19, 21, 1744-1746.

(7) Du, J.; Xing, J.; Ge, C.; Liu, H.; Liu, P.; Hao, H.; Dong, J.; Zheng, Z.; Gao, H. Highly sensitive and ultrafast deep UV photodetector based on a $\beta-\mathrm{Ga}_{2} \mathrm{O}_{3}$ nanowire network grown by CVD J. Phys. D. Appl. Phys 2016, 49, 425105.

(8) Zhao, B.; Wang, F.; Chen, H.; Wang, Y.; Jiang, M.; Fang, X.; Zhao, D Solar-Blind

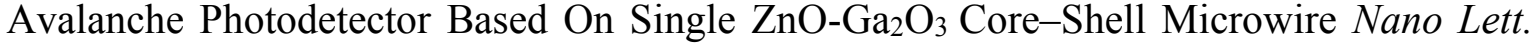
2015, 15, 6, 3988-3993.

(9) Nakagomi, S.; Momo, T.; Takahashi, S.; Kokubun, Y. Deep ultraviolet photodiodes based on $\beta-\mathrm{Ga} 2 \mathrm{O} 3 / \mathrm{SiC}$ heterojunction Appl. Phys. Lett. 2013, 103, 72105.

(10) Qian, L. X.; Liu, X. Z.; Sheng, T.; Zhang, W. L.; Li, Y. R.; Lai, P. T. $\beta-\mathrm{Ga}_{2} \mathrm{O}_{3}$ solar-blind deep-ultraviolet photodetector based on a four-terminal structure with or without Zener diodes AIP Adv 2016, 6, 4, 5009.

(11) Guo, D.; Liu, H.; Li, P.; Wu, Z.; Wang, S.; Cui, C.; Li, C.; Tang, W. Zero-PowerConsumption Solar-Blind Photodetector Based on $\beta-\mathrm{Ga}_{2} \mathrm{O}_{3} / \mathrm{NSTO}$ Heterojunction $A C S$ Appl. Mater. Interfaces 2017, 9, 619-1628.

(12) Kong, W. Y.; Wu, G. A.; Wang, K. Y.; Zhang, T. F.; Zou, Y. F.; Wang, D. D.; Luo, L. B. Graphene- $\beta-G a 2 O 3$ Heterojunction for Highly Sensitive Deep UV Photodetector Application. Advanced Materials 2016, 28, 48, 10725-10731.

(13) Chen, X.; Liu, K.; Zhang, Z.; Wang, C.; Li, B.; Zhao, H.; Zhao, D.; Shen, D. Self-Powered Solar-Blind Photodetector with Fast Response Based on Au/ $\beta-G a 2 O 3$ Nanowires Array Film Schottky Junction. ACS Applied Materials and Interfaces 2016, 8, 6, 4185-4191.

(14) Pan, S.; Liu, Q.; Zhao, J.; Li, G. Ultrahigh Detectivity and Wide Dynamic Range Ultraviolet Photodetectors Based on $\mathrm{Bi}{ }_{x} \mathrm{Sn}_{1-} \mathrm{O}_{2}$ Intermediate Band Semiconductor. ACS Applied Materials \& Interfaces 2017, 9, 34, 28737-28742.

(15) Zhu, L.; Dai, Q.; Hu, Z. F.; Zhang, X. Q.; Wang, Y. S. High response organic deep ultraviolet photodetector with PEDOT:PSS anode Opt. Lett. 2011, 36, 10, 1821-1823.

(16) Zhu, L.; Dai, Q.; Hu, Z. F.; Zhang, X. Q.; Wang, Y. S. Organic deep ultraviolet photodetector with response peak focusing on $270 \mathrm{~nm}$ using the acceptor BAlq IEEE Photonics Technol. Lett. 2011, 23, 23, 1835-1837.

(17) Wu, S. H.; Li, W. L.; Chu, B.; Lee, C. S.; Su, Z. S.; Wang, J. B.; Yan, F.; Zhang, G.; Hu, Z. Z.; Zhang, Z. Q. High response deep ultraviolet organic photodetector with spectrum peak 
focused on $280 \mathrm{~nm}$ Appl. Phys. Lett. 2010, 96, 9, 10-13.

(18) Zhang, M.; Liu, G.; Zhang, D.; Chen, Y.; Wen, S.; Ruan, S. Facile fabrication of $\mathrm{NaTaO}_{3}$ film and its photoelectric properties J. Alloys Compd. 2014, 602, 322-325.

(19) Guo, B.; Wu, G.; Chen, H. Z.; Wang, M. Solution-processed organic/inorganic hybrid photodetector with selective deep UV sensitivity Org. Electron. physics, Mater. Appl. 2016, 29, 13-21.

(20) Zhang, Q. Q.; Jie, J.; Diao, S.; Shao, Z.; Zhang, Q. Q.; Wang, L.; Deng, W.; Hu, W.; Xia, H.; Yuan, X.; Lee, S. T. Solution-Processed Graphene Quantum Dot Deep-UV ACS Nano 2015, 9, 2, 1561-1570.

(21) Pfeifer, G. P.; You, Y.-H.; \& Besaratinia, A.; Mutations induced by ultraviolet light Mutat. Res. 2005, 571, 1-2, 19-31.

(22) Khiabani, P. S.; Soeriyadi, A. H.; Reece, P. J.; Gooding, J. J. Paper-Based Sensor for Monitoring Sun Exposure ACS Sensors 2016, 1, 6, 775-780.

(23) Howie, J. A. B.; Rowles, G. K.; Hawkins, P. An inexpensive sensor for ultraviolet-A and ultraviolet-B radiation Mater. Sci. Technol. 1991, 2, 1070-1073.

(24) Dang, V. Q.; Trung, T. Q.; Duy, L. T.; Kim, B. Y.; Siddiqui, S.; Lee, W.; Lee, N. E. HighPerformance Flexible Ultraviolet (UV) Phototransistor Using Hybrid Channel of Vertical ZnO Nanorods and Graphene ACS Appl. Mater. Interfaces 2015, 7, 20, 11032-11040.

(25) Liu, Z.; Huang, H.; Liang, B.; Wang, X.; Wang, Z.; Chen, D.; Ultraviolet Photodetectors on Rigid and Flexible Substrates Optics Express 2012, 20, 3, 5145-5149.

(26) Wijeyasinghe, N.; and Anthopoulos, T. D. Copper ( I ) thiocyanate ( CuSCN ) as a holetransport material for large-area opto / electronics Semicond. Sci. Technol. 2015, 30, 104002.

(27) Tennakone, K.; Jayatissa, A. H.; Fernando, C. A. N.; Wickramanayake, S.; Punchihewa, S.; Weerasena, L. K.; Premasiri, W. D. R. Semiconducting and photoelectrochemical properties of n-and p-type $\beta$-CuCNS Phys. Status Solidi A 1987, 103, 491-497.

(28) Yaacobi-Gross, N.; Treat, N. D.; Pattanasattayavong, P.; Faber, H.; Perumal, A. K.; Stingelin, N.; Bradley, D. D. C.; Stavrinou, P. N.; Heeney, M.; Anthopoulos, T. D. Highefficiency organic photovoltaic cells based on the solution-processable hole transporting interlayer copper thiocyanate $(\mathrm{CuSCN})$ as a replacement for PEDOT:PSS $A d v$. Energy Mater. 2015, 5, 1401529.

(29) Qin, P.; Tanaka, S.; Ito, S.; Tetreault, N.; Manabe, K.; Nishino, H.; Nazeeruddin M. K.; Grätzel, M. Inorganic hole conductor-based lead halide perovskite solar cells with $12.4 \%$ conversion efficiency Nat. Commun. 2014, 5, 3834.

(30) Zhao, K.; Munir, R.; Yan, B.; Yang, Y.; Kim, T.-S.; Amassian, A.; Solution-processed inorganic copper(I) thiocyanate $(\mathrm{CuSCN})$ hole transporting layers for efficient $\mathrm{p}-\mathrm{i}-\mathrm{n}$ perovskite solar cells J. Mater. Chem. A, 2015, 3, 20554-20559.

(31) Perumal, A.; Faber, H.; Yaacobi-Gross, N.; Pattanasattayavong, P.; Burgess, C.; Jha, S.; McLachlan, M. A.; Stavrinou, P. N.; Anthopoulos, T. D.; Bradley, D. D. C. High-Efficiency, Solution-Processed, Multilayer Phosphorescent Organic Light-Emitting Diodes with a Copper Thiocyanate Hole-Injection/Hole-Transport Layer Adv. Mater. 2015, 27, 1, 93-100.

(32) Garnier, J.; Parize, R.; Appert, E.; Chaix-Pluchery, O.; Kaminski-Cachopo, A.; Consonni, V. Physical Properties of Annealed ZnO Nanowire/CuSCN Heterojunctions for SelfPowered UV Photodetectors ACS Appl. Mater. Interfaces 2015, 7, 10, 5820-5829.

(33) Hatch, S. M.; Briscoe, J.; \& Dunn, S.; A self-powered ZnO-nanorod/CuSCN UV photodetector exhibiting rapid response Adv. Mater. 2013, 25, 6, 867-871.

(34) Yang, Z.; Wang, M.; Ding, J.; Sun, Z.; Li, L.; Huang, J.; Liu, J.; Shao, J. Semi-Transparent 
ZnO-CuI/CuSCN Photodiode Detector with Narrow-Band UV Photoresponse ACS Appl. Mater. Interfaces 2015, 7, 38, 21235-21244.

(35) Petti, L.; Pattanasattayavong, P.; Lin, Y.-H.; Münzenrieder, N.; Cantarella, G.; YaacobiGross, N.; Yan, F.; Tröster G.; Anthopoulos, T. D. Solution-processed p-type copper(I) thiocyanate $(\mathrm{CuSCN})$ for low-voltage flexible thin-film transistors and integrated inverter circuits Appl. Phys. Lett. 2017 110, 113504.

(36) Chen, H.; Liu, H.; Zhang, Z.; Hu, K.; Fang, X. Nanostructured Photodetectors: From Ultraviolet to Terahertz Adv. Mater. 2016, 28, 3, 403-433.

(37) Beesley, D. J.; Semple, J.; Krishnan Jagadamma, L.; Amassian, A.; McLachlan, M. A.; Anthopoulos, T. D.; deMello, J. C. Sub-15-nm patterning of asymmetric metal electrodes and devices by adhesion lithography Nat. Commun. 2014, 5, 3933.

(38) Semple, J.; Rossbauer, S.; Burgess, C. H.; Zhao, K.; Jagadamma, L. K.; Amassian, A.; McLachlan, M. A.; Anthopoulos, T. D. Radio Frequency Coplanar ZnO Schottky Nanodiodes Processed from Solution on Plastic Substrates Small, 2016, 12, 15, 1993-2000.

(39) Semple, J.; Wyatt-Moon, G.; Georgiadou, D. G.; McLachlan, M. A.; Anthopoulos, T. D., Semiconductor-Free Nonvolatile Resistive Switching Memory Devices Based on Metal Nanogaps Fabricated on Flexible Substrates via Adhesion Lithography IEEE Trans. Electron Devices, 2017, 64, 5, 1973-1980.

(40) Pattanasattayavong, P.; Yaacobi-Gross, N.; Zhao, K.; Ndjawa, G. O. N.; Li, J.; Yan, F.; O’Regan, B. C.; Amassian, A.; Anthopoulos, T. D. Hole-transporting transistors and circuits based on the transparent inorganic semiconductor copper(I) thiocyanate $(\mathrm{CuSCN})$ processed from solution at room temperature Adv. Mater. 2013, 25, 10, 1504-1509.

(41) Pattanasattayavong, P.; Ndjawa, G. O. N.; Zhao, K.; Chou, K. W.; Yaacobi-Gross, N.; O'Regan, B. C.; Amassian, A.; Anthopoulos, T. D. Electric field-induced hole transport in copper(I) thiocyanate (CuSCN) thin-films processed from solution at room temperature.," Chem. Commun. (Camb). 2013, 49, 39, 4154-6.

(42) Semple, J.; Rossbauer, S.; \& Anthopoulos, T. D.; Analysis of Schottky Contact Formation in Coplanar $\mathrm{Au} / \mathrm{ZnO} / \mathrm{Al}$ Nanogap Radio Frequency Diodes Processed from Solution at Low Temperature ACS Appl. Mater. Interfaces, 2016, 8, 1, 23167-23174.

(43) Jaffe, J. E.; Kaspar, T. C.; Droubay, T. C.; Varga, T.; Bowden, M. E.; Exarhos, G. J. Electronic and defect structures of CuSCN. Journal of Physical Chemistry C 2010, 114, 19, 9111-9117.

(44) P. Pattanasattayavong, A. D. Mottram, F. Yan, T. D. Anthopoulos.; Study of the Hole Transport Processes in Solution-Processed Layers of the Wide Bandgap Semiconductor Copper(I) Thiocyanate (CuSCN). Advanced Functional Materials 2015, 25, 6802-6813.

(45) P. Pattanasattayavong, V. Promarak, and T. D. Anthopoulos.; Advanced Electronic Materials 2017, 3, 1600378.

(46) Kind, H.; Yan, H.; Messer, B.; Law, M.; Yang, P. Nanowire ultraviolet photodetectors and optical switches. Advanced Materials, 2002, 14, 2, 158-160

(47) Konstantatos, G.; Sargent, E. H. Nanostructured materials for photon detection Nat. Nanotechnol. 2010, 5, 6, 391-400.

(48) White, J. S.; Veronis, G.; Yu, Z.; Barnard, E. S.; Chandran, A.; Fan, S.; Brongersma, M. L. Extraordinary optical absorption through subwavelength slits. Optics Letters 2009, 34, 5, 686-8

(49) Ghimire, R. R., Nath, R., Neogy, R. K., \& Raychaudhuri, A. K. (2017). Ligand-free attachment of plasmonic $\mathrm{Au}$ nanoparticles on $\mathrm{ZnO}$ nanowire to make a high-performance 
broadband photodetector using a laser-based method. Nanotechnology, 2017, 28, 29, 295703.

\section{Table of Contents Synopsis}

A novel type of deep ultraviolet (DUV) photodetector is demonstrated based on the solutionprocessable, wide bandgap (3.5-3.9 eV) semiconductor copper(I) thiocyanate $(\mathrm{CuSCN})$ in combination with coplanar asymmetric $\mathrm{Al} / \mathrm{Au}$ nanogap electrodes realized by adhesion lithography (a-Lith). The resulting DUV photodetectors exhibit excellent operating characteristics with high responsivity and promising dynamic response. 


\section{Table of Contents Graphic}

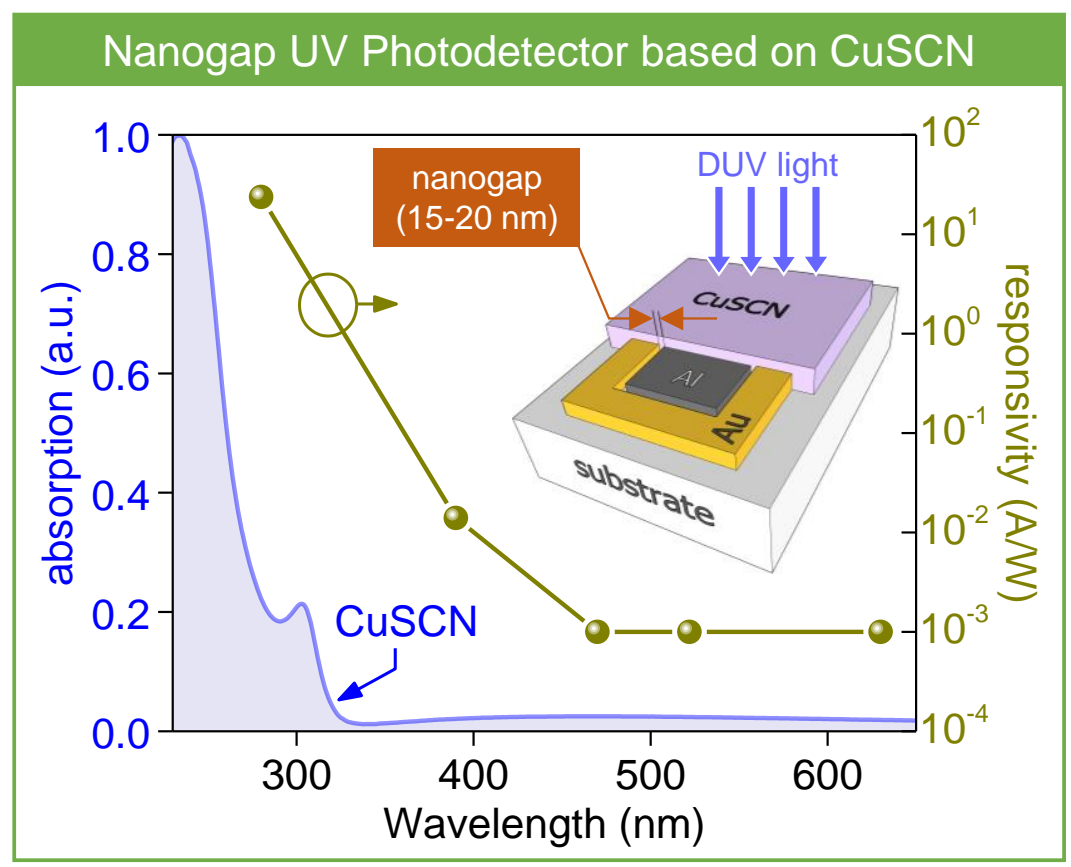

